\title{
Pulmonary infection with opportunist mycobacteria on Merseyside 1974-1983
}

\author{
H.W. Clague*, E.H. El-Ansary**, C.A. Hopkins and C. Roberts \\ Chest Diseases Unit and Public Health Laboratory Service, Fazakerley Hospital, Longmoor Lane, Liverpool, \\ L97AL, UK.
}

\begin{abstract}
Summary: During a 10 year period 49 patients were recorded as having pulmonary infection caused by opportunist mycobacteria. Six different species were identified of which $M$. kansasï (65\%) and $M$. aviumintracellulare $(20 \%)$ were the most common. Cough and sputum $(82 \%)$ or haemoptysis $(26 \%)$ were frequent symptoms on presentation and over two thirds of patients had pre-existing respiratory disease. Chest radiographs showed predominantly apical disease with the right apex $(44 \%)$ being twice as commonly affected as the left (22\%). In $30 \%$ the radiograph showed bilateral disease.

Clinicians had an individual approach to treatment with no uniform pattern of drug prescribing. $A$ majority of patients $(59 \%)$ received rifampicin for at least 9 months and those patients with $M$. kansasii infection responded well with no bacteriological relapses in 20 patients followed for a mean period of 3.9 years. $M$. avium-intracellulare, $M$. malmoense and $M$. xenopi were less responsive to treatment and in four patients receiving chemotherapy death was attributed to mycobacterial infection.
\end{abstract}

\section{Introduction}

With the decline of Mycobacterium tuberculosis infection there has been a relative increase in the isolation rate of the opportunist group of mycobacteria (Anon, 1981) and although they usually exist in the environment as saphrophytes they can give rise to opportunist infection especially in lung tissue which has already been damaged by pre-existing disease (Wolinsky, 1979). However, the disease can also occur in previously healthy subjects and in both groups the clinical picture may closely resemble tuberculosis (Wolinsky, 1979). Diagnosis relies on repeated bacteriological cultures which exist in association with the typical clinical and radiographic picture (Jenkins, 1959; Yamamoto et al., 1967). Occasionally false positive direct smears arise because of harmless colonisation of the respiratory tract (Wolinsky, 1979) or because of laboratory contamination with infected tap water (Gangadharam et al., 1976). Some opportunists like $M$. gordonae rarely produce disease whereas $M$. avium-intracellulare can cause a chronic debilitating illness, resulting in death.

Despite the potential seriousness of some of these

*Correspondence and present address: H.W. Clague, B.Sc., M.D., M.R.C.P. Department of Medicine, Bishop Auckland General Hospital, Bishop Auckland, Co. Durham DL14 6AD, UK.

**Present address: Sennar Hospital, Sennar, Sudan Accepted: 20 November 1985 pulmonary infections, there is no general consensus as to when and how they should be treated (Wolinsky, 1979). Recent reports suggest that $M$. kansasii infections can be effectively treated with a combination of rifampicin and ethambutol, given for a period of 15 months (Banks et al., 1983), whereas M. aviumintracellulare may require quadruple therapy for a much longer period (Hunter et al., 1981).

This recognized uncertainty about diagnosis and treatment prompted us to examine our own experience on Merseyside over a 10 year period, from 1974-1983. We set out to look at the pattern of pulmonary disease associated with different isolates of opportunist mycobacteria and to determine whether on treatment there was any uniform pattern of drug prescribing.

\section{Patients and methods}

Specimens or isolates from patients suspected of having mycobacterial infection on Merseyside are sent to the Liverpool Regional Public Health Laboratory at Fazakerley Hospital for culture, identification and sensitivity testing by standard methods. In certain cases cultures are sent to the Mycobacterium Reference Unit in Cardiff for further identification and sensitivity tests.

The study was restricted to pulmonary infection during the period 1974-1983. Patients from whom

(C) The Fellowship of Postgraduate Medicine, 1986 
three or more sputum isolates of an opportunist mycobacterium were recovered, were identified and their clinical records examined. Only patients with multiple isolates of one species of mycobacterium in the absence of any concurrent infection including $M$. tuberculosis, were included. Furthermore the chest radiographs were reviewed and had to show radiographic abnormalities compatible with mycobacterial infection. In those cases where the chest radiograph was not available a description of the radiographic abnormalities was obtained indirectly from notes made by the clinician or reporting radiologist.

One patient was included on post-mortem evidence of a pure isolate of $M$. malmoense and histological evidence of active mycobacterial infection. Treatment was considered successful if there was a satisfactory clinical course, radiographic abnormalities remained stable and if the sputum became negative.

\section{Results}

There were 49 opportunist mycobacterial infections recorded between 1974 and 1983 and this compares with 1215 notifications for $M$. tuberculosis during the same period. The bacteriological distribution of the opportunist infections is shown in Table I. M. kansasii was most commonly implicated $(65 \%)$ followed by $\boldsymbol{M}$. avium-intracellulare $(20 \%)$. The average age of the patients was 62.3 years (range $31-89$ ) and most were men $(86 \%)$. A smoking history was available for 43 patients and only one was a life-long non-smoker, the rest being current (40 patients) or ex- ( 2 patients) smokers. Symptoms were often insidious and masked by symptoms due to coexisting lung disease (Table II). The most common presenting complaints were cough and sputum $(82 \%)$ or haemoptysis $(26 \%)$. Twentyfour per cent had lost weight but only $6 \%$ had experienced fever. Four per cent were asymptomatic and diagnosed on routine chest radiography. Chronic bronchitis and emphysema or previous $M$. tuberculosis infection were the most commonly associated lung diseases (Table II) although lung cancer was an associated condition in 5 patients. Radiographic abnormalities included infiltration, cavitation and fibrosis, indistinguishable from $M$. tuberculosis infection. With one exception apical disease predominated with the right apex (44\%) being twice as commonly affected as the left $(24 \%)$. In $30 \%$ the disease was bilateral.

Of 32 patients with $M$. kansasii infection 24 received chemotherapy which included rifampicin for at least 9 months with three quarters of these patients having between 9 and 12 months of daily rifampicin. Seventeen of these patients also received ethambutol for at least nine months. In all a total of ten different drug combinations were used. Follow up ranged from 1 to 9
Table I The distribution of organisms in 49 cases of opportunist mycobacterial infection

\begin{tabular}{lc}
\hline Organism & No. of patients \\
\hline M. kansasii & 32 \\
$M$. avium-intracellulare & 10 \\
$M$. xenopi & 3 \\
$M$. malmoense & 2 \\
$M$. fortuitum & 1 \\
$M$. gordonae & 1 \\
\hline
\end{tabular}

years (mean 3.9) in the 20 patients for whom details were available. No bacteriological relapses were noted. One patient had rifampicin and ethambutol for 6 months and died 8 years later with no evidence of activity. Three patients died of unrelated causes whilst on treatment. Only one patient was left untreated and he remained smear positive for 2 years until lost to follow up. Another patient with scanty growth on culture was left untreated for 18 months, but treatment was then started because of worsening symptoms and because increasing numbers of $M$. kansasii were isolated on culture.

The outcome and treatment of the 10 patients with $M$. avium-intracellulare infection is detailed in Table III. In general, response to treatment was poor and compliance with second line agents doubtful. In patient 1 , mycobacterial infection was a contributory cause of death. Patients 2 and 3 died whilst on? treatment, the former from a mycobacterial empyema following surgical resection and the latter from massive haemoptysis. Patients 4, 5 and 6 died of unrelated causes. Only patient 10 is known to be alive and free of disease.

The treatment and outcome of the remaining cases is detailed in Table IV. The two patients with $M$. malmoense and the one case with $M$. gordonae isolates have been reported in detail elsewhere (Roberts et al., 1985; Clague et al., 1985). One of the M. malmoense infections was found at post-mortem, whilst the other

Table II Associated lung disease in patients with opportunist mycobacterial infection

\begin{tabular}{lc}
\hline & $\begin{array}{c}\text { No. of } \\
\text { patients }\end{array}$ \\
\hline Chronic bronchitis and emphysema & $24^{*}$ \\
Previous $M$. tuberculosis infection & 7 \\
Lung cancer & 5 \\
Bronchiectasis & 1 \\
Basal fibrosis & 1 \\
Pneumoconiosis & 1 \\
\hline
\end{tabular}

*7 patients also had other lung diseases. 
Table III Treatment and outcome in 10 pateints with M. avium-intracellulare 2 infection

\begin{tabular}{|c|c|c|c|c|c|}
\hline Patient & $\begin{array}{l}\text { Treatme } \\
\text { (months, }\end{array}$ & $t \&$ duration & $\begin{array}{c}\text { Sputum } \\
\text { conversion }\end{array}$ & $\begin{array}{l}\text { Length of } \\
\text { follow-up } \\
\text { (years) }\end{array}$ & Outcome \\
\hline 1 & & Nil & No & 2 & $\begin{array}{l}\text { Contributed } \\
\text { to death }\end{array}$ \\
\hline 2 & $\begin{array}{l}\mathbf{R} \\
\mathbf{H}(2) \\
\mathrm{Z}\end{array}$ & $\begin{array}{l}\mathrm{Z} \\
\text { PRO (10) } \\
\text { CYC }\end{array}$ & No & 1 & $\begin{array}{c}\text { Death } \\
\text { (empyema) }\end{array}$ \\
\hline 3 & $\begin{array}{l}\mathrm{H}(4) \\
\mathrm{E}\end{array}$ & & No & $<1$ & $\begin{array}{c}\text { Death } \\
\text { (haemoptysis) }\end{array}$ \\
\hline 4 & $\begin{array}{l}R \\
H(1) \\
E\end{array}$ & $\begin{array}{l}\mathbf{R} \\
\text { CYC (7) }\end{array}$ & No & 2 & $\begin{array}{l}\text { Unrelated } \\
\text { death }\end{array}$ \\
\hline 5 & $\begin{array}{l}R \\
H(4) \\
E\end{array}$ & $\begin{array}{l}\text { PRO } \\
\text { L (4) }\end{array}$ & No & 6 & $\begin{array}{l}\text { Unrelated } \\
\text { death }\end{array}$ \\
\hline 6 & $\begin{array}{l}\mathbf{R} \\
\mathrm{H}(12) \\
\mathrm{E}\end{array}$ & & Unknown & 4 & $\begin{array}{l}\text { Unrelated } \\
\text { death }\end{array}$ \\
\hline 7 & $\begin{array}{l}R \\
H(6) \\
E\end{array}$ & $\begin{array}{l}\mathbf{R} \\
\text { THIO (6) } \\
\text { H }\end{array}$ & No & 3.5 & $\begin{array}{l}\text { Failing } \\
\text { health }\end{array}$ \\
\hline 8 & $\begin{array}{l}R \\
\text { H (2) } \\
\text { E }\end{array}$ & $\begin{array}{l}\text { R } \\
\text { CYC (3) } \\
\text { ETH }\end{array}$ & Yes & 0.5 & Unknown \\
\hline 9 & $\begin{array}{l}\mathbf{R} \\
\mathrm{H}(9) \\
\mathrm{E}\end{array}$ & & No & 0.75 & Unknown \\
\hline 10 & $\begin{array}{l}R \\
H(4) \\
E\end{array}$ & $\begin{array}{l}\mathrm{R} \\
\text { CYC (12) }\end{array}$ & Yes & 6 & $\begin{array}{c}\text { Alive, } \\
\text { disease } \\
\text { free }\end{array}$ \\
\hline
\end{tabular}

$\mathrm{R}=$ rifampicin $\mathrm{H}=$ isoniazid, $\mathrm{E}=$ ethambutol, $\mathrm{Pro}=$ prothionamide, $\mathrm{Cyc}=$ cycloserine, $\mathrm{Eth}=$ ethionamide $\mathrm{L}=$ lamprene, Thio $=$ thiosemicarbazone, $Z=$ pyrazimanide .

patient continued to deteriorate over a period of 4 years despite multiple drug chemotherapy. The patient with $M$. gordonae infection died of a small cell carcinoma of the bronchus whilst on treatment. One patient with $M$. xenopi infection was left untreated and died 6 months later. Another death occurred in an elderly male on treatment. His chest radiograph was unique in showing predominantly basal changes with broinchiectasis and a cavitating pneumonia. The third patient with $M$. xenopi infection remains well on chemotherapy.

The patient with $M$. fortuitum infection had four isolates and post-radiation fibrosis of the right upper lobe, but in addition had superimposed pneumonic infiltration with cavities. She was initially considered to have $\boldsymbol{M}$. tuberculosis infection and chemotherapy with ethambutol and isoniazid was continued for a period of 2 years with no progression of disease. She died a further 3 years later from a carcinoma of the pancreas, with no further isolates of $M$. fortuitum.

\section{Discussion}

In this series opportunist mycobacterial infections accounted for $3.9 \%$ of the total number of cases of pulmonary mycobacterial infections compared to $2.9 \%$ as quoted by Jenkins (1981) for Wales during the period 1952-1978. The bacteriological distribution, with $M$. kansasii and $M$. avium-intracellulare being numerically the most important, was also similar. A previous B.T.T.A. Study (1974) stressed the importance of occupational dust exposure in the genesis of pulmonary $\boldsymbol{M}$. kansasii infection, but this was not a feature of our study. Of 32 patients with $M$. kansasii 
Table IV Treatment and outcome in 7 patients with opportunist mycobacterial infection

\begin{tabular}{|c|c|c|c|c|c|c|c|c|}
\hline Patient & Organism & & Treatme & $\begin{array}{l}\text { and dur } \\
\text { nths) }\end{array}$ & & $\begin{array}{c}\text { Sputum } \\
\text { conversion }\end{array}$ & $\begin{array}{l}\text { Length of } \\
\text { follow-up } \\
\text { (years) }\end{array}$ & Outcome \\
\hline 11 & M. malmoense & $\begin{array}{l}\text { R } \\
\text { PRO } \\
\text { H (18) } \\
\text { E }\end{array}$ & $\begin{array}{l}\text { ETH } \\
\text { E (9) }\end{array}$ & $\begin{array}{l}\text { R } \\
\text { H } \\
\text { E (2) } \\
\text { CAP }\end{array}$ & $\begin{array}{l}\text { Z } \\
\text { CAP (6) }\end{array}$ & Yes & 4 & $\begin{array}{c}\text { Clinically well but } \\
\text { radiograph deteriorated } \\
\text { to involve whole of RUL }\end{array}$ \\
\hline 12 & M. malmoense & & & & & & & Post-mortem diagnosis \\
\hline 13 & M. xenopi & nil & & & & No & & $\begin{array}{l}\text { Contributed to death } \\
\text { at } 6 \text { months }\end{array}$ \\
\hline 14 & M. xenopi & $\begin{array}{l}S(1) \\
R(3) \\
H\end{array}$ & & & & No & & Continues with treatment \\
\hline 15 & M. xenopi & $\begin{array}{l}\mathrm{R} \\
\mathrm{H}(1) \\
\mathrm{E}\end{array}$ & & & & No & & Died at one month \\
\hline 16 & M. fortuitum & $\begin{array}{l}\mathrm{E}(24) \\
\mathrm{H}\end{array}$ & & & & Yes & 3 & Unrelated death \\
\hline 17 & M. gordonae & $\begin{array}{l}\mathrm{R} \\
\mathrm{H}(4) \\
\mathrm{E}\end{array}$ & & & & Yes & & $\begin{array}{l}\text { Unrelated death } \\
\text { during treatment }\end{array}$ \\
\hline
\end{tabular}

Abbreviations as Table III and CAP $=$ capromycin, $\mathrm{S}=$ streptomycin, $\mathrm{RUL}=$ right upper lobe.

infection only one patient was a miner with certifiable pneumoconiosis and five others were general or dock labourers whose occupational history did not suggest an unusually high dust exposure. Almost two thirds of the patients were males, aged between $40-70$ years, a pattern of susceptibility documented by others (Wolinsky, 1979).

Current cigarette smoking appeared to be an important aetiological factor in the development of opportunist infection, but previous work suggests that this is no more than in mycobacterial disease in general (Ortbals \& Marr, 1978). Previous studies have emphasized the importance of pre-existing lung damage to the development of opportunist infection and this probably explains the association with cigarette smoking. In 14 of the cases with $M$. kansasii infection there was no previous record of respiratory disease but this does not exclude sub-clinical degrees of emphysema related to cigarette smoking (Seaton \& Ogilvie, 1978). The importance of obstructive lung disease as an aetiological factor has been emphasized by others (Wolinsky, 1979; Banks et al., 1983) and is confirmed by the present study. Chronic air flow limitation seems especially important in the case of opportunist mycobacteria as Ahn et al. (1976) have shown that ventilatory defects are more frequently seen in patients with $M$. kansasii infection than in comparative groups with $M$. tuberculosis. Ten per cent of the study group had coexisting lung cancer and this was again presumably related to cigarette smoking. In one study (Feld et al., 1976) the opportunist mycobacteria accounted for over $50 \%$ of mycobacterial infections in patients with concomitant malignancy, although others have suggested (Wolinsky, 1979) that malignancy is a predisposing condition of equal force for all types of mycobacterial disease.

Comments made about the chest radiographs seem to support the evidence (Wolinsky, 1979) that there are no reliable radiographic differences between disease caused by opportunist mycobacteria and $M$. tuberculosis, although others (Zvetina et al., 1984) believe that distinguishing features do exist. A propensity for the organisms to infect the lung apex is a well known feature (Wolinsky, 1979) confirmed by the present study. This upper zone preference is surprising as the opportunist mycobacteria show little consistent preference in vitro for the characteristic upper lobe concentration of gases (Chapman, 1982). The upper zone predominance may relate to pre-existing lung damage since the two most common associated conditions, that is previous tuberculosis and emphysema induced by cigarette smoking, both occur at the lung apex.

In the majority of cases, clinicians accepted multiple 
mycobacterial isolates in the presence of radiographic abnormalities as indicative of infection but there was little consensus as to the choice of drug regimen or duration of treatment. Numerically the two most important infections in the present study were $M$. kansasii and $M$. avium-intracellulare. As might be predicted from previous publications (Wolinsky, 1979) M. kansasii responded well to chemotherapy. Recommendations differ as to the duration of treatment but periods of up to two years have been suggested (Wolinsky, 1979). Banks et al. (1983) have reported good results in 35 patients with $M$. kansasii infection given rifampicin and ethambutol for a period of 15 months. The efficacy of rifampicin is well documented (Harmis et al., 1975) and its frequent inclusion in the present study probably explains the success of regimens of only 6 to 12 months.

The outcome of $M$. avium-intracellulare infection following treatment was less predictable and could, in part, be attributed to the presence of coexisting serious debilitating diseases, such as malignancy or end stage respiratory failure. Hunter et al. (1981) have reported that adequate treatment can be achieved by using isoniazid, rifampicin and either ethambutol or streptomycin for at least 9 months but more reliably by giving 24 months therapy. Others (Wolinsky, 1979) have found a high relapse rate with multiple drug regimens and recommend combining drug therapy with surgical resection. Sensitivity results should always be interpreted jointly by clinician and bacteriologist and in many cases it may be advisable to treat empirically with standard chemotherapy rather than use potentially toxic drugs that are poorly tolerated and result in an inadequate duration of chemotherapy.

$M$. xenopi and $M$. malmoense have only recently been appreicated as important pulmonary pathogens (Roberts et al., 1985; Simor et al., 1984). In both, the response to treatment can be poor and unpredictable and again at variance with the results of in vitro sensitivity tests. Banks et al. (1984) have reported a series of 47 patients of pulmonary infection caused by $M$. xenopi. Resection was performed in five patients with a resulting cure in four, leading them to suggest that resection might be part of first-line treatment and should usually be performed if patients fail to respond to initial chemotherapy, or if they relapse. $M$. malmoense appears to behave like $M$. avium-intracellulare in responding poorly to chemotherapy (Roberts et al., 1985).

$M$. fortuitum and $M$. gordonae are considered to be rare causes of pulmonary disease and the cases reported here underline the difficulty of differentiating invasive disease from harmless colonisation. It would seem prudent to give chemotherapy when there are multiple isolations in the presence of high risk predisposing factors, such as malignancy, particularly if specific treatment of a malignancy is being considered.

In conclusion, opportunist mycobacteria may exhibit a wide range of pathogenicity and susceptibility to chemotherapy. Uncertainty as to the ideal mode of treatment has led to widely different prescribing habits and we would endorse previous recommendations (Banks et al., 1983; Hunter et al., 1981) that there is a need for prospective multi-centre planned chemotherapy trials.

\section{Acknowledgements}

We wish to thank Mrs Margie Knotts for typing the manuscript, Mr R. Griffiths for technical assistance, and our clinical colleagues for allowing us to include their cases.

\section{References}

AHN, C.H., NASH, D.R. \& HURST, G.A. (1976). Ventilatory defects in atypical mycobacteriosis. American Review of Respiratory Disease, 113, 273.

ANDERSON, D.H., GRECH, P., TOWNSHEND, R.H. \& JEPHCOTT, A.E. (1976). Pulmonary lesions due to opportunist mycobacteria. Clinical Radiology, 26, 461.

ANON. (1981). Opportunist mycobacteria. Lancet, i, 424.

BANKS, J., HUNTER, A.M., CAMPBELL, I.A., JENKINS, P.A. SMITH, A.P. (1983). Pulmonary infection with Mycobacterium kansasii in Wales, (1970-9): review of treatment and response. Thorax, 38, 271.

BANKS, J., HUNTER, A.M., CAMPELL, I.A., JENKINS, P.A. \& SMITH, A.P. (1984). Pulmonary infection with Myobacterium xenopi: a review of treatment and response. Thorax, 39, 376.

BRITISH THORACIC AND TUBERCULOSIS ASSOCIATION. (1974). Opportunist mycobacterial pulmonary infection and occupational dust exposure: an investigation in England and Wales. Tubercle, 56, 295.
CHAPMAN, J.S. (1982). The atypical mycobacteria. American Review of Respiratory Disease, 125, 119.

CLAGUE, H.W., HOPKINS, C.A., ROBERTS, C. \& JENKINS, P.A. (1985). Pulmonary infection with Mycobacterium gordonae in the presence of bronchial carcinoma. Tubercle, 66, 61 .

FELD, R., BODEY, G.P. \& GROSCHEL, D. (1976). Mycobacteriosis in patients with malignant disease. Archives of Internal Medicine, 136, 67.

GANGADHARAM, P.R.J., LOCKHART, J.A., AWE, R.J. \& JENKINS, D.E. (1976). Mycobacterial contamination through tap water. American Review of Respiratory Disease, 113, 894.

HARMIS, G.D., WALDEMAR, G., JOHANSON, J.R. \& NICHOLSON, D.P. (1975). Response to chemotherapy of pulmonary infection due to Mycobacterium kansasii. American Review of Respiratory Disease, 112, 31.

HUNTER, A.M., CAMPBELL, I.A., JENKINS, P.A. \& SMITH, A.P. (1981). Treatment of pulmonary infections caused by 
mycobacteria of the Mycobacterium avium-intracellulare complex. Thorax, 36, 326.

JENKINS, P.A. (1981). The epidemiology of opportunist mycobacterial infection in Wales, (1952-1978). Review of Infectious Diseases, 3, 1021.

JENKINS, D.E. (1959). Recent clinical studies in the United States on atypical acid fast bacilli. Bulletin of the International Union of Tuberculosis, 29, 295.

ORTBALS, D.W. \& MARR, J.J. (1978). A comparative study of tuberculous and other mycobacterial infections and their associations with malignancy. American Review of Respiratory Disease, 117, 39.

ROBERTS, C., ClAGUE, H.W. \& JENKINS, P.A. (1985). Pulmonary infection with Mycobacterium malmoense: a report of 4 cases. Tubercle, 66, 205.

SEATON, D. \& OGILVIE, C. (1978). Regional lung function in asymptomatic cigarette smokers. American Review of Respiratory Disease, 118, 265.

SIMOR, A.E., SALIT, I.E. \& VELLEND, H. (1984). The role of Mycobacterium xenopi in human disease. American Review of Respiratory Disease, 129, 435.

WOLINSKY, E. (1979). Nontuberculous mycobacteria and associated diseases. American Review of Respiratory Disease, 119, 107.

YAMAMOTA, M., SUDO, K., TAGA, M., HIBINO, S. (1967). A study of diseases caused by atypical mycobacteria in Japan. American Review of Respiratory Disease, 96, 779. ZVETINA, J.R., DEMOS, T.C., MALIWAN, N., DRUNEN, M.V., FREDERICK, W., LETINO, J. \& MODH, A.M. (1984). Pulmonary cavitations in Mycobacterium kansasii, distinctions from M. tuberculosis. American Journal of Radiology, 143, 127. 